\title{
What about the context in family medicine?
}

\section{INTRODUCTION}

The conclusion of the Alma-Ata Declaration in 1978 was strong and persuasive:

'The international conference on primary health care (...) strongly reaffirms that health, which is a state of complete physical, mental, and social well-being, and not merely the absence of disease or infirmity, is a fundamental human right and that the attainment of the highest possible level of health is a most important worldwide social goal whose realisation requires the action of many other social and economic sectors in addition to the health sector."

Numerous studies on health differences document the fact that socioeconomic conditions influence people's health. ${ }^{2-3}$ Including the context is a deliberate choice in family medicine. Typically, family medicine consists of contact with the whole family system. Family physicians are generalists. They have a long-term commitment, and very often there is a close relationship between doctor and patient, leading to an accumulation of knowledge over many years. ${ }^{4}$ Does this mean that contextual family medicine addresses the social determinants as formulated in the broad Alma-Ata definition, and how is this being done? In this article we focus on two health centres: one in Belgium and one in the Netherlands. Both health centres are situated in socioeconomically deprived areas. What can be learned from research on more than 30 years established practice of community-based health care?

\section{THE IMPORTANCE OF SOCIAL DETERMINANTS}

In primary health care, professionals, in principle, have a long-lasting relationship with the inhabitants of the neighbourhood: there are many encounters over a long period. This is the case with chronic patients, multi-problem families, but also with healthy people. Although nowadays there is a strong emphasis (coming from efficiency-logic) on short interventions in health care, an essential feature of primary health care is that people living in the neighbourhood have contact with professionals from various perspectives: there is contact with primary care, at the birth of a child, during the education of a child, in the case of sport injuries, when a hernia occurs, at times of 'flu', when caring for a sick family member, when relational problems occur, when there are financial difficulties, at times of depression. Through this continuous relationship, information and knowledge accumulate but there are also links established between primary care and individuals, households and sometimes extended families. These people are not only in relationship with healthcare providers, but they also construct mutual relationships and interactions. A neighbourhood is a conglomerate of different social networks. A social network is a group of people to which an individual is linked in order to achieve certain aspirations. Household and family (first circle), friends, working relationships (second circle), and social services (third circle), are part of this network. Primary care is part of these networks in the neighbourhood. The significance of social networks has been studied thoroughly in theories in relation to 'social capital'. Putnam and other, experts on social capital, make the distinction between closed and open networks. In closed social networks with a bonding social capital, the interaction of people is orientated inwards, with the aim of maintaining exclusivity, and with a 'particularised' trust. This may lead to isolation. In open networks, with a 'bridging social capital', people are orientated outwards. Open networks stimulate people to transcend the boundaries and to enrich themselves with information, knowledge, and other resources in a broader context. The presence of 'bridging capital' contributes to linkages between groups and communities and starts from a 'generalised' trust. ${ }^{5-6}$

The health centre 'Samen Beter' in the Den Bosch-Oost in the Netherlands has devoted specific attention to the importance of social networks for health. ${ }^{7}$ Social support and informal care have an impact in the neighbourhood, that cannot be offered by professional care, but, in general, are not sufficiently valued by professional care. The case 'De Stroom' in Box 1 illustrates the influence of social networks and the significance they have for health.

Characteristics of the communityoriented approach are: joining the living

\section{Box 1. Case 'De Stroom'.}

De Stroom (meaning stream or river) started at the end of the 80s in the neighbourhood of 'Den Bosch-Oost' as an initiative of some of the inhabitants as well as care providers of the health centre 'Samen Beter'. The aim was to give women with serious psychosocial and psychiatric problems in the neighbourhood sufficient support and help. These women consult family physicians very frequently. 'De Stroom' offers tailored care programmes, that are developed jointly by professionals and volunteers. The contact with other women, the mutual trust, enables women to decide to participate in parts of the programme, such as self-help groups, creative and educative groups, or relaxation groups. The use of 'experience-based-knowledge' of volunteers, with the support of professionals, has been labelled as 'duo-care'. Evaluation documented a steady increase in the self-confidence of the women, participating in the programme. It was concluded that the programme avoided institutionalisation in psychiatry. Moreover, the frequency of visits to the family physician decreased, but the main result was that the women learned to discover their capabilities. They went through a process of 'empowerment'. 
conditions of the people in the neighbourhood and the initiation of sustainable relationships.

In the literature 'community' is defined as 'a group of people who share common aspects in their lives'. These aspects can be related to living conditions, common interests, culture, norms and values. This is related to those aspects that are of real importance for the people. ${ }^{9}$

The community-orientation and the focus on the neighbourhood, has been central in the development of the health centre 'Botermarkt' in Ghent. The centre uses the model of 'Community Oriented Primary Care' for a systematic intervention in a neighbourhood by knowing the 'epidemiological community' (health indicators and socioeconomical indicators), knowing the 'anthropological community' (characteristics and opinions of the different groups in societies), and the 'support community' (supporting networks of professionals and informal care). ${ }^{10}$

Primary healthcare workers look for relevant data and for signals in the daily practice; they analyse existing data (surveys) and collect new data, both qualitative and quantitative, via interviews, surveys and daily registration. When developing intervention programmes, based on a 'community diagnosis', targetgroups are involved. By so doing, the health centre contributes to a comprehensive approach at the level of the neighbourhood; for example, through improved access to care and the development of emancipatory care, linked to the values, norms, capabilities, and limitations of the target group. The case in Box 2 'physical health' illustrates this approach.

In a study for the Knowledge Network on Health Systems of the Commission on Social Determinants of Health of the World Health Organization, it became clear that primary health care is able to address the social economic differences in health. This requires a reorientation of primary care, not only with a focusing on the individual and the family, but also with a focus on the local community. Intersectoral action for health is required. Strategies are 'empowerment' of individuals, their families and communities and the strengthening of the 'social cohesion'. ${ }^{12}$ These strategies need a mix of long-lasting, intensive relationships and short repeating contacts between residents, volunteers, and professionals. Those relationships, and the presence of accessible health care in the neighbourhood, with special attention for socially deprived groups, may influence health positively. The family physician can play an important role due to his 'signal function"12 and through referral to community initiatives. By doing so, family physicians can contribute to the strengthening of the 'social capital' of inhabitants and improvement of care. The World Health Report 2008 'Now more than ever' also calls 'to respond better and faster - to the challenges of a changing world. Primary health care should do that as a key constituent of the architecture of contemporary societies'. ${ }^{3}$

\section{Box 2. Physical health.}

The family physicians and nurses of the community health centre Botermarkt discovered that the physical condition of youngsters in the neighbourhood was worsening: this was very apparent during the physical examination of the children. A survey of the neighbourhood showed that children spent twice as long in front of the television and playing videogames as the average Flemish child, and that they were spending only half as much time on physical activity. A meeting was organised for all the people involved, including youth organisations, schools and parents, in order to discuss these findings. The 'community diagnosis' became very clear: for a population of almost 9000 people in $1 \mathrm{~km}^{2}$, there were no green spaces, no playgrounds for the children. A group of volunteers decided to construct a playground on a piece of ground that was made available by the city of Ghent and activities were organised for the children during the summer holidays. The evaluation showed numerous outcomes following this intervention: there were clear signals of improved social cohesion (half of the children who participated in the activities were of migrant origin), and the physical condition of the youngsters improved. Moreover, there was a request from the Turkish mothers who accompanied the children to the activities: they asked for a course on 'Know your body'. ${ }^{11}$

\section{CONCLUSIONS AND CONSIDERATIONS ABOUT 'CONTEXTUAL EVIDENCE'}

To change the social conditions of people is one of the strategies that is neither wellresearched nor underpinned by facts in primary care. How could this research be performed?

The randomised control trial (RCT), in the health sector, is considered as the gold standard in order to assess effects of interventions. The RCT documents causality between intervention and effect, but is very often limited to simple problems (one disease with one treatment), tested within a restricted group of people (for example, people without comorbidity). It is impossible to investigate a communityapproach in a controlled research design. The 'community intervention trial' (CIT) is a follow-up of the RCT and is an experimental research design. In this methodology, groups are the unit of research, whereas in the RCT, individuals are the unit of research. Still the dynamics of community-oriented work are conflicting with the 'rigour' of the research design of pre-test, post-test, intervention-group, and control group, based on a relatively static context.

To understand the complexity of the context, you need diverse forms of knowledge. Professionals, volunteers, and residents have different kinds of knowledge available, knowledge based on scientific, professional, or experiential approaches. ${ }^{13}$ Creation of knowledge between professionals and volunteers (with their experiential knowledge) are possible in a neighbourhood because a community brings together the different capacities and shares personal knowledge. To create 'community-related knowledge' there is a need to integrate 'contextual evidence ${ }^{114}$ in the research design, there is a need for both quantitative and qualitative data, there is a need for scientific and professional knowledge, a need for experiences and for possibilities to exchange experiences. Moreover, there is need for recognition of the diversity in knowledge, because that is a prerequisite for exchange. In order to do this, it is necessary to elaborate on the concept of 'contextual evidence'. The remaining questions are numerous. What is the 
meaning of 'context'? How can this be integrated in the care process? What is the relationship between contextual evidence and ethical issues? At the same time there is a need to assess whether or not the actual developments in health care (more market forces, pay-for-performance, outsourcing of care, diagnostic-treatmentcombinations) contribute to the integration of 'contextual evidence'. There is need for guidance in the reflection on data and experiences, and there is a need for practices to implement the new knowledge. This may be an opportunity for interdisciplinary health centres to take the lead.

\section{Mariet Paes and Jan De Maeseneer}

\section{REFERENCES}

1. World Health Organization. Declaration of Alma-Ata, International Conference on Primary Health Care, Alma-Ata, USSR, 6-12 September 1978. Geneva:
World Health Organization, 1978.

http://www who int/hpr/NPH/docs/declaration_alma ata.pdf (accessed 27 Nov 2009).

2. Mackenbach JP. Health inequalities: Europe in profile United Kingdom Presidency of the EU. Rotterdam: Erasmus MC, 2006

3. World Health Organization. The World Health Report 2008, Primary Health Care: Now More Than Ever. Geneva, World Health Organization, 2008 http://www.who.int/whr/2008/en/index.html accessed 27 Nov 2009).

4. McWhinney IR. A textbook of family medicine. New York, NY: Oxford University Press, 1989.

5. Portes A. Social capital: its origins and applications in modern sociology. Annu Rev Sociol 1998; 24: 1-24.

6. Putnam RD, Feldstein LM. Better together. Restoring the American community. New York, NY: Simon \& Schuster, 2004

7. Paes M. Gezondheid op menselijke maat. Over de positie en rol van gezondheidscentra in achterstandswijken. [Health in a human way. About the position and role of health centres in deprived neighbourhoods]. Zwolle: National Centre for Community Development, 1999.

8. Paes M. Wijkgezondheidswerk. Een studie naar 25 jaa wijkgericht werken aan gezondheid in Den Bosch-Oost. [Community based health work. A study of 25 years community based health approach in Den BoschOost]. 's-Hertogenbosch, Provincial Council of Community Health and Social Care of Noord-
Brabant, 2008.

9. Alting DEM, Bouwens J, Keijsers JEFEM. Review: community-interventions. Woerden: Netherlands Institute for Health Promotion and Disease Prevention (NIGZ), 2003.

10. Rhyne R, Bogue R, Kukulka G, Fulner H. Community-oriented primary care: health care for the 21st century. Washington, DC: American Association for Public Health, 1998.

11. Art B, Deroo L, De Maeseneer J. Towards unity for health: utilising community oriented primary care in education and practice. Educ Health 2007; 20(2): 74.

12. De Maeseneer J, Willems S, De Sutter A, et al. Primary health care as a strategy for achieving equitable care: a literature review commissioned by the Health Systems Network of CSDH (Commission on Social Determinants of Health), 2007. http://www.who.int/social_determinants/resources/cs dh_media/primary_health_care_2007_en.pdf (accessed 24 Nov 2009).

13. Duyvendak JW, Kremer M. Policy, people and the new professional. De-professionalisation and reprofessionalisation in care and welfare. Amsterdam: Amsterdam University Press, 2006.

14. De Maeseneer JM, van Driel ML, Green LA, van Wee C. Translating research into practice 2: the need for research in primary care. Lancet 2003; 362:1314-1319.

DOI: 10.3399/bjgp10X482176

\section{COMMENTARY}

Addressing the social and economic determinants of health is largely an upstream task, beyond the scope of practitioners working on the front line, even if as Henry E Sigerist wrote, 'they are well aware of the factors which confound all their efforts'. ' What then is the role of GPs and family doctors in addressing the social and economic determinants of health? The usual answer ('not much') is insufficiently imagined. Primary care could do lots more.

First, although most clinical care needs to take account of the social context, this is most true and necessary for patients with multiple problems, as found particularly in deprived areas. Practitioners whose lives are separate from those of their patients are less likely to understand this context. There is a clear challenge for education, training, and continuing professional development.

Second, the social capital and trust that is built up via long-term relationships between practitioners and patients is a crucial resource when discussing preferences and choices, especially in old age, when the consequences of impersonal care may result in healthcare experiences and expenditure that no one really wants.

Thirdly, as populations get older, it is clear that the problems of looking after people cannot and should not be over-professionalised. While services may be resource poor, communities are potentially people rich. In facing the challenges of ageing populations, professionals need to work in new ways with communities, reducing professional distance, while increasing partnership and accountability.

In these ways, practitioners can be important social and economic determinants of health in the populations they serve. Whether they perceive themselves in this way, and provide examples such as those described by Paes and De Maeseneer, ${ }^{2}$ and pioneered by the likes of Sam Everington ${ }^{3}$ and Scott Murray ${ }^{4}$ in the UK, depends less on their professional knowledge and expertise, than on their values, on how they see their professional role and on their relationships with patients and communities. As yet we have only a few wild flowers, but with time, imagination and effort, this part of primary care could surely bloom.

\section{Graham Watt}

\section{REFERENCES}

1. HE Sigerist. Medicine and human welfare. New Haven, CT: Yale University Press, 1941.

2. De Maeseneer J, Paes M. What about the context in family medicine? Br J Gen Pract 2010; 60: 56-58.

3. Social Enterprise Ambassadors. Sam Everington. http://socialenterpriseambassadors.org.uk/ambassadors/ambassador-details?amb=37 (accessed 1 Dec 2009 ).

4. Murray SA, Graham LJC. Practice based needs assessment: use of four methods in a small neighbourhood. BMJ 1995; 310:1443-1448. 